\title{
La deforestación en \\ el norte de Esmeraldas (Eloy Alfaro y San Lorenzo)
}

Pablo Aníbal Minda Batallas*

\section{Introducción}

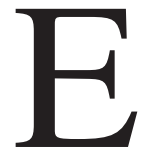

1 presente artículo no pretende ser una exposición exhaustiva de los problemas relacionados con la tala del bosque y los aspectos a él vinculados desde la perspectiva forestal, como suele ser común en algunos círculos de opinión, que miran en el bosque más que cualquier otra cosa la riqueza forestal con fines de extracción maderable para dedicarla a la industria de contra chapados y otras aplicaciones que pueda tener en la industria maderera del país y del exterior.

Este más bien se centra en un análisis socio histórico de cómo la región fue vinculada a la Sociedad Nacional y como esta (la región) se vinculó con la Sociedad Nacional y los procesos socio económicos de esta; los procesos socio económicos e históricos que han tenido y tienen lugar en la región, la emergencia de actores sociales locales y los efectos que estos procesos han tenido sobre la deforestación del bosque en los cantones Eloy Alfaro y San Lorenzo.

\section{La región}

\subsection{Ubicación y características ecológicas}

Para comprender la gravedad que implica la deforestación del bosque en el norte de la provincia de Esmeraldas que corresponde a los cantones Eloy Alfaro y San Lorenzo, es necesario conocer su inmensa riqueza ambiental y ecológica que alberga.

En general la provincia de Esmeraldas se encuentra ubicada en el noroccidente del Ecuador, entre las coordenadas de longitud: $78.28^{\circ}$ y

"Coordinador del Proyecto de Desarrollo Rural de la Provincia de Esmeraldas. 
$80.5^{\circ}$ y de latitud: $01.27^{\circ}(\mathrm{N})$ y $00.01^{\circ}(\mathrm{S})$. Limita al Occidente con el océano Pacífico, al Norte con el Departamento de Nariño - Colombia, al Oeste y Sur con las provincias de Carchi, Imbabura, Pichincha y Manabí.

En cuanto al clima, Esmeraldas es una provincia que se podría caracterizar como húmeda, cuya pluviosidad anual oscila entre los $800 \mathrm{~mm}$ - 1200 mm; muy húmeda con una pluviosidad anual de hasta 2000 mm; y superhúmeda con pluviosidad anual de hasta $5500 \mathrm{~mm}$. La humedad de la provincia aumenta tanto hacia el Sur, como al interior y Norte, de tal manera que los cantones Eloy Alfaro y San Lorenzo (al área a la que se refiere este artículo) donde se encuentran localizadas la mayor parte de áreas protegidas se caracterizan por ser "superhúmedas".

La temperatura en toda la provincia se encuentra alrededor de los $25^{\circ} \mathrm{C}$., siendo cálido seco y cálido húmedo, sobre todo al Norte 1 .

Ecológicamente la zona se encuentra en el área del Chocó Biogeográfico que tiene su origen en Panamá y se extiende hasta Manabí, y en el que se ha identificado uno de los 25 hot spots más importantes de la Tierra. En el Chocó Biogeográfico Ecuatoriano se han identificado once zonas de vida, siendo una de las diez unidades más biodiversas del Neotrópico. Esta micro región se encuentra en la zona de vida de Bosque Húmedo Tropical (bht) y Bosque muy húmedo tropical (bmht) (Holdridge, 1983), citado por (Fundación Natura, 1995).

Se estima que en esta zona el número total de especies de flora llega alrededor de las 6300 (aproximadamente el 25\% de la flora del país), de las cuales 1260 son probablemente endémicas de zona (Dodson \& Gentry, 1993) citado por (Minda, 1999,9) y existen 650 especies de aves de las 1 500 reportadas en el país.

La importancia ecológica de la subregión está determinada porque en ella se encuentran las áreas protegidas más importantes de la provincia de Esmeraldas como son: la Reserva Ecológica Cotacachi-Cayapas (con una superficie de 204420 ha de las cuales 161130 corresponden a los cantones Eloy Alfaro y San Lorenzo); la Reserva Forestal Awá, (con una superficie de 101000 de las que 28160 se encuentran en el cantón San Lorenzo) y la Reserva Ecológica Manglares Cayapas-Mataje (con 51300 ha) $)^{\text {, }}$, todas

1 Todos los datos referentes a clima, temperatura, etc. han sido tomados del trabajo de Sabine Speiser, Tenencia de la Tierra en Esmeraldas, publicado por el FEPP en 1983.

2 Esta Reserva últimamente ha sido declarada reserva Ramsar, con lo cual su manejo tiene una mayor posibilidad de ser llevado adelante. 
ellas dentro de los cantones Eloy Alfaro y San Lorenzo. Además, en el año 1998 se creó el bosque protector del Yalaré con una extensión de 1 050 ha, como un intento de proteger los humedales de la zona.

En relación al bosque, cabe anotar que estos dos cantones tienen una extensión de 728600 ha, de la cuales 488500 pertenecen a Eloy Alfaro y 240100 a San Lorenzo, las mismas que de acuerdo a su uso se encuentran repartidas de la siguiente manera: ${ }^{3}$

\section{Cuadro No. 1}

Aptitud de Uso de la tierra en Eloy Alfaro y San Lorenzo ${ }^{4}$

\begin{tabular}{|l|l|}
\hline Áreas de uso especial & 244289,70 ha \\
\hline Áreas de uso agropecuario & $211248,50 \mathrm{ha}$ \\
\hline Patrimonio Forestal del Estado & $273061,80 \mathrm{ha}$ \\
\hline
\end{tabular}

Fuente: Unidad Coordinadora

Elaboración: El autor

Es necesario indicar que, al momento la distribución que consta en el cuadro anterior ya no existe, pues las presiones realizadas por los distintos sectores han determinado que, especialmente las áreas de Patrimonio Forestal sean cada vez disminuidas, contribuyendo a la deforestación de la zona.

\subsection{El paisaje humano y cultural del norte de Esmeraldas}

Los cantones Eloy Alfaro y San Lorenzo, se encuentran habitados por población afro ecuatoriana, la misma que se encuentra asentada en la zona desde el siglo XVI. Esta se encuentra básicamente situada en los ríos: Bogotá, Tululbí, Cachabí, Santiago, Cayapas, Onzole, San Lorenzo, Limones, etc. Los indígenas Chachi, cuya presencia en la zona data del siglo XV (Savoia, 1988), y se encuentran ubicados en los ríos: Tulul-

\footnotetext{
3 Unidad Coordinadora, 1996, 6.

${ }^{4}$ Las áreas de uso especial corresponden a las reservas antes anotadas.
} 
bí, en la parte media y alta del río Cayapas y Onzole e indígenas Emberá o Epera que se encuentran situados en la parroquia de Borbón e indígenas Awá que se encuentran dentro de la reserva étnica del mismo nombre y cuya ubicación está en San Lorenzo, y población colona migrante de todo el país. Tales grupos se han asentado en la región en distintas épocas, acorde como la zona se fue abriendo al interés nacional y la posibilidad de explotar sus recursos naturales y colocarlos en los distintos mercados ya sean locales, nacionales o externos.

Se debe anotar además que, en estos momentos, en los dos cantones se encuentran asentadas importantes empresas dedicadas al cultivo de la palma africana, empresas de contrachapados que se dedican a la extracción de la madera; así como un incipiente sector turístico que ha empezado a instalarse en el balneario de las Peñas; asimismo y como una consecuencia de la inestabilidad y los conflictos en Colombia, tanto en San Lorenzo como en Eloy Alfaro se da la presencia de inmigrantes colombianos que vienen huyendo de la situación de violencia del país del norte; con lo cual mucho de esa violencia se ha trasladado al norte de Esmeraldas 5 .

Todos estos grupos humanos tienen una cultura propia con la cual se acercan a la naturaleza y al bosque. Tanto para los grupos indígenas, como para los afro descendientes, es válida la definición de René Orellana en el sentido de que la tierra, el bosque no son entendidos como un bien desagregado de la naturaleza, sino como un todo entramado, donde todos los elementos interactúan unos con otros. Como él define:

No es una cosa, o conjunto de cosas utilizables, explotables, no es un conjunto de recursos, en el sentido utilitario e instrumental, la naturaleza es un ente vivo que proporciona medios de auto reproducción. Alrededor de esta concepción el hombre construye un conjunto de creencias y valores, que se expresa en prácticas, hábitos y lenguajes. (Orellana, R: 1999.94)

5 Durante el año pasado y en lo que va de este año los asesinatos de personas se hicieron presentes especialmente en San Lorenzo. De tal manera que la población conjuntamente con al alcalde de la ciudad realizaron una marcha por la ciudad en protesta de los asesinatos que se comenten en la ciudad. Muchos de estos asesinatos fueron reportados por la prensa nacional como el caso del Teniente político de Mataje con el que murieron 7 personas incluida una niña de 15 años. 
Las comunidades afro descendientes, tienen una cultura holística donde todo está integrado, formando un todo complejo y armónico. $\mathrm{Al}$ respecto, Martha Escobar sostiene que:

"Tanto en el plano del pensamiento, como en la vida misma de ese grupo, el bien y el mal, lo natural y lo sagrado, la vida y la muerte, el espíritu y la materia, lo real y lo imaginario constituyen un continúan dentro del cual ningún elemento está escindido. Así: los hombres, los animales, las plantas, los elementos, las divinidades, los espíritus de los muertos, las visiones, están inmersos equitativamente en la totalidad, en esa universalidad, todos los niveles se cruzan e interrelacionan". (Escobar, M: 1990).

Esta perspectiva cultural se expresa en la siguiente figura, en la que se explicita la especialización cosmogónica del uso del territorio y el universo afro ecuatoriano.

Figura No. 1

\section{Especialización Cosmogónica del Territorio en el Universo Afro}

Mundo arriba sin pecado

Mundo divino

Cielo Ciol

Cielo estelar

Cielo atmosférico

Mundo terrenal

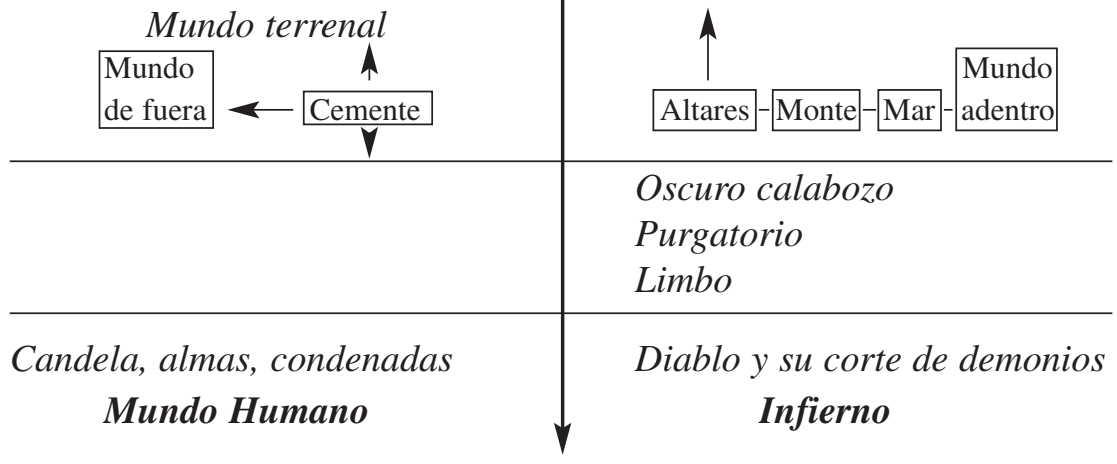

Mundo abajo del pecado 
Los campesinos migrantes en general son portadores de una cultura que se podría definir como ecuatoriana con sus respectivas especificidades, dependiendo del lugar del cual sean originarios, los primeros colonos provenientes de Ibarra y el Carchi, se asentaron a partir de la década del 60 cuando se sostenía que:

"El norte de Esmeraldas, es una región potencial para la colonización proveniente de las áridas montañas de Carchi e Imbabura. La colonización es ciertamente una esperanza grande para ingenieros y planificadores y, aparentemente también, para un número mayor de serranos de clase baja... El sueño de una tierra nueva, rica, libre, cálida y amistosa, atrajo a mucha gente hace unos ocho años cuando el ferrocarril abrió por primera vez, una vía entre Ibarra (la capital de Imbabura) y San Lorenzo. De hecho, el ferrocarril todavía atrae gente interesada en asentarse en una tierra rica, o en acumular una fortuna y regresar a la sierra".

Ellos se autoidentifican como ecuatorianos genéricamente y luego como manabas, orenses, etc. Se autodefinen también como agricultores, que han venido buscando la tierra para trabajar y poder vivir. Respecto del problema de la destrucción de la naturaleza ellos están conscientes que hay que cuidarla.

"Yo como dirigente, y he hablado con varias personas, me han hecho entender esto, porque yo tengo mis treinta años, pero nunca me he percatado de que hay que cuidar los árboles, pero en este momento nosotros hemos aceptado cuidar los árboles, toda la gente que vive en esta comunidad está consciente de eso, por eso nosotros pedimos de que se nos ayude, se nos asesore, y si tenemos por ejemplo unas 50 ha estamos de acuerdo que con 30 podemos hacer de agricultura y 20 podemos mantenernos en árboles, que eso nos sirve para beneficio tanto para el Estado, para el medio ambiente y para nosotros mismos".

Son esta cantidad de actores que tienen diferentes percepciones culturales respecto de la naturaleza, el bosque, los recursos naturales, la vida; los que han llevado adelante complejos procesos socio políticos y económicos en la región que a la larga han contribuido a la destrucción progresiva del bosque y de los recursos naturales en su conjunto. Todo esto mediado por la presencia del Estado, que en unos momentos ha sido de actor protagónico y en otros de observador casi pasivo, pero nunca ausente, aunque lo parezca y otros se lo crean (lo veremos más adelante).

6 C.F.R. Whitten, N., 1997, 37-38.

7 Entrevista a José Quiroz, quien fue dirigente de un importante grupo de campesinos blancos mestizos de ubicados en la vía Borbón San Lorenzo. 


\section{La visión del Estado sobre el Noroccidente del Ecuador}

Una de las cuestiones que explica los procesos de tala del bosque en el norte de Esmeraldas, léase destrucción de la naturaleza, y consecuentemente de las formas de vida de los pueblos asentados en la región con anterioridad a la conquista y la colonia, es la forma como esta ha sido mirada y construida por parte del Estado Nacional y los sectores dominantes, en sus diferentes etapas históricas; porque de esta mirada y de esta construcción, que se realiza desde una cultura específica y de unos intereses concretos, depende como se incorpora un área territorial al conjunto de lo que se denomina país o nación. Esta incorporación puede ser realizada desde una perspectiva de equidad y de respeto a las diferencias o desde la inequidad, la imposición y la dominación.

\subsection{La visión de la colonia}

De acuerdo a los datos que conocemos, la región de lo que hoy es el norte de Esmeraldas, representó para los interese de la colonia un lugar estratégico, para sus intereses, pues para la Audiencia de Quito implicaba la posibilidad de tener un camino corto al mar, con lo cual lograba la independencia de los puertos de Guayaquil y El Callao, así como la posibilidad de tener puestos para el auxilio a los naufragios que se producían en esta zona. Lo mismo que significa hoy: cercanía al mar y a los mercados de Colombia (Speiser: 1991; 81). (Minda, 1998, 3).

Por esta razón uno de los primeros proyectos que tuvo la colonia en relación a la región fue la construcción un camino que una esta zona con la Audiencia de Quito de manera efectiva. Con la apertura del camino se buscaba, además de tener controlada a la población que se había mostrado difícil de someter, especialmente los alzamientos de Alonso de Illescas, quien estableció en Esmeraldas una verdadera República de Sambos y de la cual llegó a ser incluso nombrado gobernador (Savoia, R: 1988); también aprovechar la existencia de los recursos naturales de la región para paliar los problemas económicos que tenía la Audiencia de Quito. Como se colige de un informe del Presidente de la Real Audiencia de Quito de la época.

“...Aún es susceptible de mayores ventajas la navegación por el río de Santiago a la mar si se fija la vista política y mercantil en los ramos de cacao; algodón blanco y amarillo; maderas exquisitas tanto de cons- 
trucción como de todas otras especies; Palo María, para arboladuras, etc., de que abundan las selvas ricas y vírgenes de este río. Estos tres artículos bastarían para eslabonar un lucroso giro con la Capital del Perú y con la Metrópoli por Panamá y Acapulco, cuya navegación con estos dos puertos es tan breve, fácil y segura, aun en tiempo de guerra, como larga y arriesgada la de Guayaquil..." (Savoia, R., 260). De esto se colige que el interés no solo era la construcción del camino, sino el aprovechamiento de los recursos naturales abundantes que existían en la región.

La construcción del camino a Esmeraldas, fue intentado varias veces, la primera ruta se abrió por primera vez entre 1616 y 1619, bajo la dirección de Pablo Durango de Delgadillo (Corregidor de Ibarra desde 1611), este camino tuvo que cerrarse debido a los constantes ataques de los Malabas. Entre 1623 y 1628 el capitán Francisco Pérez trató de reabrir dicho camino, sin conseguirlo, debido a la presencia belicosa de los Malabas y por la oposición del Virrey de Lima que temía que con este camino se daba atractivos a los Piratas (Speiser: 1991; 81).

Es Pedro Vicente Maldonado que en 1730 trazó un camino que bordeaba el río Esmeraldas para evitar la presencia combativa de los Malabas, sin embargo este también fue cerrado por orden del Virrey de Lima, después de 1748 año de la muerte de Maldonado.

Posteriormente, en los siglos XVII y XVIII, el régimen colonial se interesó en la construcción de un Puerto Marítimo en la costa del Pacífico, en el extremo noroccidental de los límites de la Real Audiencia de Quito (San Lorenzo) y en la apertura de una vía que partiendo desde Quito arribara al océano Pacífico, por el delta del Santiago, siguiendo por la cuenca del río Lita. Este proyecto tenía el propósito de vincular los centros de producción textil de la sierra norte con los puntos de articulación comercial con Europa, ubicados en la costa norte del Pacífico (Popayán y Buenaventura). De este modo se pensaba facilitar y agilizar las exportaciones y evitar la dependencia con los puertos de Guayaquil y el Callao.

Con esto queda explicitada la visión de la colonia respecto de esta región; era un espacio para extraer recursos económicos, de vinculación con los mercados; pero además fue un espacio de conflictos políticos con la sociedad "Samba "con quienes la Corona tuvo que negociar y hacerles varias concesiones con la finalidad de incorporarles a la colonia y lograr su lealtad ${ }^{8}$.

\footnotetext{
8 Para una comprensión de la problemática de la sociedad zamba entre el siglo entre los siglos XVI y XVIII se recomienda el texto ya citado de Rocío Rueda: "Zambaje y Autonomía".
} 


\subsection{La visión del Estado en la República}

El Estado ecuatoriano, ya en la vida republicana, tampoco renunció a la incorporación de Esmeraldas (especialmente el Norte) al dominio pleno del aparato estatal, para lo cual se utilizaron distintos mecanismos. El fin de alguna manera era el mismo: uso y posesión de los recursos y sujeción de la población.

En 1857 la empresa Land Ecuador Company, mediante contrato con el Estado ecuatoriano, cuyo presidente era José María Urbina obtuvo en San Lorenzo del Pailón la cantidad de 100000 ha de tierra, igual cantidad que obtuvo en Atacames, con lo cual se pretendía pagar una parte de la deuda inglesa de la independencia. Dicha adjudicación permitía a la empresa explotar todos los recursos, sin que nada ni nadie tenga posibilidad alguna de presentar reclamo. Al respecto el contrato de adjudicación (pág. 604) dice: “...transfiere... todo el dominio y propiedad de la predichos terrenos, con todas sus acciones útiles, derechos reales, personales y mixtos" y que nadie la inquietará, despojará, ni moverá pleito alguno, sobre su propiedad, posesión, uso y más derechos anexos" (cit. por Speiser en Op.cit., 67). Esto le permitió a la empresa, a más de la explotación directa de los recursos, arrendar a distintas casas comerciales para que exploten los distintos productos, sobre todo los que tenían demanda en el mercado internacional, entre ellos la tagua, el caucho, la cáscara de mangle y maderas, construyendo así el primer enclave económico en la región y su vinculación con le mercado mundial; y por supuesto, el primer momento de una deforestación selectiva, pues la empresa extraía maderas finas para la venta al exterior, igual que la tala de mangle para la extracción de su corteza.

A lo largo de todo el siglo XIX y XX el Estado no cejó en su intento de una total incorporación de la región al modelo de desarrollo de la sociedad nacional, con la finalidad de extraer los recursos existentes en ella, al margen de los efectos que estos procesos tengan para las poblaciones locales y la naturaleza de la que ellos dependen en alta medida para su supervivencia. Los proyectos más significativos en la República han sido:

\section{a) La construcción del ferrocarril}

Otro hecho importante que alteró drásticamente a la sociedad y al entorno natural de la región, es la construcción del ferrocarril Ibarra- 
San Lorenzo y del puerto marítimo en San Lorenzo. Propuesta, que data desde la colonia y obedece a similares propósitos: a) Necesidad de establecer un puerto para el comercio internacional de bienes producidos en la sierra centro y norte del Ecuador, con el fin de abaratar costos de transporte y romper con la dependencia con los grupos económicos guayaquileños; b) acceder a los abundantes recursos naturales del bosque húmedo tropical y c) abrir en la región espacios de colonización, como alternativa para solucionar conflictos de tierra surgidos en otras regiones del país, resultado de procesos históricos de concentración de la propiedad, con el desplazamiento de población pobre de las áreas rurales.

La construcción del tendido vial y la llegada del ferrocarril tuvo efectos significativos sobre la población y el entorno natural, que se tradujo en:

* Desplazamiento de población local de las áreas colindantes al tendido vial del ferrocarril.

* Apropiación de tierras por trabajadores y colonos en áreas colindantes a la vía, avalado y propiciado por el Estado. La Empresa de Ferrocarriles, determina y delimita como zona de colonización una franja de 10 kilómetros de territorio a cada lado de la vía.

* Procesos sostenido de deforestación, orientada a: a) delimitación de áreas de posesión de migrantes, b) implementación de sistemas agrícolas y ganaderos en pequeñas escalas y c) comercialización de madera (para durmientes de la vía del ferrocarril) (Robalino, M, 2003).

\section{b. La entrega de las concesiones madereras Proyecto DEFORNO}

Una vez creadas las condiciones básicas, <especialmente por la construcción del ferrocarril, para convertir a la región en centro de producción de recursos naturales, especialmente madera, en la década de los sesenta, el Estado Ecuatoriano, en la lógica del modelo de industrialización (sustitución de importaciones), propone la realización de un estudio que viabilice la integración de la región norte de Esmeraldas al circuito de producción nacional e internacional como productor de recursos naturales forestales. 
Estudio que establece la existencia de abundantes recursos forestales susceptibles de ser extraídos para su comercialización, evidencia las falencias técnicas y financieras para alcanzar el propósito; que deben ser superadas con la participación del Estado, empresa privada y organismos internacionales.

Este estudio, quizá sea el factor "subjetivo" de mayor impacto sobre el bosque en la zona norte de la provincia de Esmeraldas, en tanto, le convierte en área de alta potencialidad de extracción forestal (en un millón de ha de "monte alterado e inalterado existen cerca de 50 millones de metros cúbicos de madera potencialmente comercial en árboles de 40 cm más de diámetro" y de 500 especies forestales, de las cuales hay 230 con potencial comercial) (Robalino: M, 2004, 8-10).

Para este efecto era necesario: garantizar seguridad sobre la tenencia de la tierra forestal, preparar personal profesional y técnico, obtener asesoramiento técnico de organismos internacionales y de países con mayor desarrollo en el tema, disponer de mano de obra local calificada, mejorar la gestión forestal estatal, incentivar la inversión mediante tratamiento especial, construir y mantener infraestructura vial, mejorar los sistemas tecnológicos de explotación y procesamiento, establecer nuevas industrias y mejorar la competitividad de las empresas nacionales. Esto determinó que el Estado el 5 de octubre de 1966 promulgue la Ley de Concesiones Forestales y entregó 14 concesiones forestales en el noroccidente del Ecuador, con lo cual se daba paso a la deforestación intensiva con fines comerciales.

\section{El proyecto palmicultor}

Este es uno de los proyectos de mayor envergadura en cuanto se refiere a la tala del bosque y es una continuación de la dinámica de penetración del gran capital agro industrial a la zona; pues en base a un estudio realizado por la ORSTOM en la década del 70 y que estableció un mapa de uso del suelo, donde se determina que las tierras del cantón San Lorenzo son aptas para el cultivo de palma africana. A partir del año de 1998 se empezó la implementación de este proyecto que tiene como finalidad la implantación de entre 30 y 40000 ha de palma africana (Minda: P, 30).

Este Proyecto, ha producido uno de los efectos más graves en relación a la deforestación; no solo por cuanto para su establecimiento 
tiene que realizar una tala rasa del bosque, con lo que destruye toda forma de vida de los ecosistemas, sino por la cantidad enorme de conflictos que creó y sigue creando con las comunidades vecinas, sobre todo por los procesos de compra de tierras, tanto de las comunas afro ecuatorianas e indígenas, así como por las compras a personas individuales . Esto ha sido más grave cuanto que, las comunidades y algunas personas que vendieron sus tierras, en muchos casos se dedicaron a invadir las tierras de otras comunidades, con la finalidad de reponer lo vendido o simplemente dedicarse al tráfico de tierras ${ }^{10}$.

El efecto de este proyecto no termina ahí; mediante decreto Ejecutivo 2961 del 8 de agosto de 2002, presidente de la república Gustavo Noboa modificó las áreas de Patrimonio Forestal, ampliando la frontera agrícola en aproximadamente 40000 ha con lo cual el proyecto tiene las posibilidad de expandirse y el bosque sufrir una mayor deforestación a tala rasa en la extensión antes indicada.

Todos los proyectos antes reseñados, no en toda su magnitud, configuran una visión del Estado y de la sociedad nacional sobre la región de permanente penetración y de incorporación de sus recursos y de su población a los circuitos del capital nacional e internacional dependiendo de las coyunturas de los precios. Este complejo proceso de incorporación - resistencia de la población a los proyectos emprendidos por las elites nacionales es la causa de la deforestación del bosque en el norte de Esmeraldas y que se trata en detalle en el siguiente apartado.

\section{La deforestación en el norte de Esmeraldas}

De acuerdo a Sierra: (1996, 9-17) para comprender el problema de la deforestación existen dos generalizaciones, con énfasis en los agentes de cambio de uso del suelo y en el uso del recurso, estas son:

Deforestación causada principalmente por la expansión de la frontera agrícola.

\footnotetext{
9 Para un análisis completo de los conflictos ver mi estudio "identidad y Conflicto: La Lucha por la Tierra en el Norte de Esmeraldas"

10 Este es el caso de la comunidad de Ricaurte que vendió sus tierras a una empresa palmicultora y posteriormente tuvo conflictos de invasión de tierras con la Reserva Awá.
} 
Deforestación causada principalmente por la tala comercial de madera.

En relación a la primera generalización basándose en varios modelos como el de Henkel, Sierra afirma, que está acorde con los modelos multifase de colonización pionera y de cambio en el uso del suelo y de los recursos naturales. En este caso los agentes de cambio serían campesinos pobres que emigran de zonas económica y ecológicamente deprimidas, que abren (deforestan) la frontera agrícola.

El modelo de Henkel, de acuerdo a Sierra (op cit, 10) tendría las siguientes etapas:

Una fase pionera que empieza con actividades de tumba y actividades agrícolas limitadas.

En una segunda fase, luego de los primeros uno diez años del asentamiento original, durante la fase de comercialización, se incrementa la accesibilidad a los mercados y la tumba se acelera para lograr que tanta tierra como sea posible entre a producir.

La tercera fase es la de consolidación, se hace evidentes las limitaciones ecológicas para el desarrollo agrícola. Muchos colonos abandonan sus fincas y se mudan a otra frontera agrícola de colonización; mientras los más exitosos consolidan sus tierras.

La fase final, la fase de revitalización, es intensiva en capital y se presenta mientras llega la agricultura a gran escala.

Por su parte la segunda generalización tendría, dos fases a saber:

En la primera fase, las operaciones madereras selectivas a gran escala abren vías en el bosque primario para la extracción de tipos específicos de madera. En el proceso, entre el 50 y $75 \%$ del dosel del bosque se destruye por la tumba y construcción de vías; mientras que en una segunda fase, tras la tala comercial se produce el asentamiento de finqueros migrantes a través de vías abiertas en la fase previa y de tala de bosques ya usados selectivamente. Ahora, lo más importante, es que las vías no solamente hacen posible el acceso a nuevas tierras, sino que la tala misma reduce los costos del asentamiento ya que la tierra previamente talada requiere de menor trabajo que un bosque intacto (Sierra: R, op cit, 11). Esto es justamente lo que ha sucedido en San Lorenzo con el proyecto palmicultor, pues de alguna manera, las empresas palmicultoras compraron tierras que habían sido previamente taladas de manera selectiva con fines de extraer madera que tenía valor comercial.

Una cuestión importante a señal es que estos dos modelos no se presentan puros, si no de manera simultánea, la clave está en saber cual 
de los factores expansión agrícola o tala comercial del bosque guían el inicio de la del bosque.

Un aspecto de vital importancia me parece importante señalar y es que como lo señala Sierra citando Rudel para cualquiera de estas dos generalizaciones se presenta un modelo institucional de la deforestación y que él denomina "el modelo de coaliciones de crecimiento/ instituciones líderes".

"Se desarrollan arreglos sociales específicos para facilitar el acceso a la tierra en la frontera agrícola. En estos arreglos, agentes con recursos -es decir, el Estado, empresas, individuos ricos-, de manera intencional o no, facilitan el avance de campesinos pobres a la frontera. Las coaliciones de crecimiento son organizaciones cuyo objetivo recoger esfuerzos incluyendo el soporte político, económico y administrativo para llevar adelante el asentamiento y la adquisición de tierras. Las instituciones líderes actúan unilateralmente para abrir una región y los colonos potenciales toman ventajas de estas acciones. En este contexto las empresas madereras han sido tradicionalmente conceptualizadas como las instituciones conductoras porque abren vías hacia la frontera y facilitan el ingreso de los finqueros" (Sierra, op cit, 13).

Lo anotado en la cita anterior tiene una aplicación exacta a lo sucedido en el norte de Esmeraldas, solo falta anotar el rol decisivo que ha tenido el Estado en proceso de deforestación de la Región como se verá más adelante.

\subsection{El período antes de 1970}

De los estudios que se conocen sobre la región (Rivera, 1986; Espeiser, 1991; Whitten, Jr 1997; Sierra, 1996.......) todos coinciden en anotar que antes de 1970 no había empezado la tala agresiva del bosque en el norte de Esmeraldas, si bien se extraían maderas finas desde la época misma de la colonia: Esto es así por cuanto este período coincide con el de extracción de materias primas que había empezado prácticamente desde la colonia vinculadas al mercado externo, como la tagua, la extracción de oro, la cáscara de mangle, caucho, maderas finas, balsa, etc., que necesitaban que el bosque se mantenga en pie para poder seguir extrayendo sus recursos. Y si bien se había instalado el cultivo del banano, éste tuvo importancia en lo que es la Comuna Río Santiago Cayapas, río Onzole, río Bogotá y el área de influencia de la carretera de vía 
Esmeraldas -La Tola, de tal manera que para 1974 solo el 6\% de la hoya del Santiago estaba bajo algún tipo de práctica agrícola (Sierra, Op cit, $50)$.

El período de deforestación se intensifica a partir en la década del 70 cuando se sientan las bases para llevar adelante un proceso de explotación expansivo, pero también intensivo del bosque. Para la época ya se había terminado la construcción del ferrocarril, con el cual la zona se abrió a la colonización. Está la época donde la migración creció de manera significativa, la misma que obedecía a una política del Estado como una forma de desactivar los conflictos sociales que se empezaban a producir en otras regiones del país.

Desde 1950 hasta 1974 la población en el cantón San Lorenzo pasa de 20470 habitantes a 41352 , con una tasa de crecimiento anual superior al 3.5\%, La cabecera parroquial de San Lorenzo desde 1962 hasta 1974 incrementa su población de 2382 a 6767 (4 385, en 12 años), con una tasa de crecimiento superior al $14 \%$, la cabecera parroquial de Borbón en el mismo período pasa de 581 habitantes a 1228 . La actividad agrícola en 1962 asimilaba a 7169 trabajadores en 1974 a 6 494; el comercio, en el mismo período, pasa de 264 a 567, servicios de 577 a 710 y la industria manufacturera de 574 a 1801 (Robalino: op cit, 11).

Pero lo más significativo en término de la deforestación tiene que ver con la Ley de Concesiones Forestales de 5 de octubre de 1966, que permite concesionar el bosque a empresas madereras para su extracción . El impacto de estas concesiones se hará sentir en la siguiente década cuando prácticamente se triplicó las áreas deforestadas. Lo cual también significó la destrucción de los ecosistemas, de la economía y de las formas sociales de los pueblos indígenas y afro ecuatorianos asentados en al región (me detendré más adelante sobre el tema). A continuación presento los datos correspondientes a las concesiones realizadas.

11 En total fueron 14 concesiones que se entregaron por 554000 ha, 13 de las cuales estaban en el noroccidente, con un total de 402000 ha (Carrasco: E, 1983, 60) citando un documento del MAG de 1978. 
Cuadro No. 2

Concesiones vigentes en el noroccidente 1978

\begin{tabular}{|c|c|c|c|c|c|c|}
\hline $\begin{array}{l}\text { Nombre } \\
\text { de la } \\
\text { compañía }\end{array}$ & $\begin{array}{l}\text { P l a n } t \text { a } \\
\text { industrial }\end{array}$ & $\begin{array}{l}\text { Concesión } \\
\text { ha }\end{array}$ & $\begin{array}{l}\text { Fecha de } \\
\text { concesión }\end{array}$ & $\begin{array}{l}\text { Área } \\
\text { explotada } \\
\text { por año }\end{array}$ & $\begin{array}{l}\text { Reforesta- } \\
\text { ción }\end{array}$ & $\begin{array}{l}\text { P a o } \\
\text { derechos } \\
\text { superfi- } \\
\text { ciarios }\end{array}$ \\
\hline $\begin{array}{l}\text { Pliw ood } \\
\text { Ecuatoria- } \\
\text { na S. A. }\end{array}$ & $\begin{array}{l}\text { Q u i t o, } \\
\text { Quinindé, } \\
\text { Canandé }\end{array}$ & 12280 & 13-VI-73 & & 1.350 & $\begin{array}{l}\text { Cancelado } \\
\text { jn/77 }\end{array}$ \\
\hline $\begin{array}{l}\text { Guayaquil } \\
\text { Pliwood }\end{array}$ & Guayaquil & 43477 & $7-V-68$ & & No & $\mathrm{No}^{*}$ \\
\hline $\begin{array}{l}\text { Industria } \\
\text { Maderera } \\
\text { Robalino }\end{array}$ & $\begin{array}{l}\text { Quito, } \\
\text { San } \\
\text { Lorenzo }\end{array}$ & 10806 & 2-III-73 & 1.300 & No & $\begin{array}{l}\text { Parcial } \\
\text { retrasado }\end{array}$ \\
\hline $\begin{array}{l}\text { Industria } \\
\text { Forestal } \\
\text { Cayapa }\end{array}$ & $\begin{array}{l}\text { G u a y a - } \\
\text { quil, Eloy } \\
\text { Alfaro }\end{array}$ & 212699 & 8-VII-68 & & No & $\mathrm{No}^{* *}$ \\
\hline EDINCA & $\begin{array}{l}\text { Quito, } \\
\text { San } \\
\text { Lorenzo }\end{array}$ & 5100 & 8-VIII-68 & & & $\begin{array}{l}\text { No tomó } \\
\text { posesión }\end{array}$ \\
\hline FORESA & $\begin{array}{l}\text { Sto } \\
\text { Domingo, } \\
\text { Quinindé }\end{array}$ & 10502 & 31-III-76 & & & $\mathrm{No}^{* * *}$ \\
\hline
\end{tabular}

Fuente: Carrasco: E., 1983: 64

Elaboración: El autor

* No cumplió ni una sola de las cláusulas contractuales. Para la fecha mantenía una deuda con el Estado de 541 518,54 (en sucres de ese entonces).

** La concesión abarcaba más del $60 \%$ de los bosques de Eloy Alfaro y San Lorenzo. Adeudaba por derechos superficiarios 218 230,70 (sucres) al 30 de junio/76.

*** Adeuda 73 514,oo al 31-dic./77, por derechos superficiarios. Se abastece comprando madera a los colonos que no se posesionaron de parte del área concesionada.

A continuación presento, cual era la situación de las concesiones en trámite para el año de 1978. 
Cuadro No. 3

Concesiones en trámite 1978

\begin{tabular}{|c|c|c|c|c|c|}
\hline $\begin{array}{l}\text { Compa- } \\
\text { ñía }\end{array}$ & $\begin{array}{l}\text { Planta } \\
\text { i n d u s - } \\
\text { trial }\end{array}$ & $\begin{array}{l}\text { Superfi- } \\
\text { cie ha }\end{array}$ & $\begin{array}{l}\text { Capacidad } \\
\text { indu } \\
\text { m }^{3} / a n ̃ o\end{array}$ & $\begin{array}{l}\text { Ubicación } \\
\text { de la conce- } \\
\text { sión }\end{array}$ & Observaciones \\
\hline $\begin{array}{l}\text { Chapas y } \\
\text { Maderas } \\
\text { S. A. }\end{array}$ & \begin{tabular}{|l} 
San \\
Lorenzo
\end{tabular} & 25000 & 11000 & Borbón* & $\begin{array}{l}99.4 \% \text { de las accio- } \\
\text { nes son de Ind } \\
\text { Cayapas. } \\
\text { Se deja insubsisten- } \\
\text { te el trámite. }\end{array}$ \\
\hline CREART & $\begin{array}{l}\text { Borbón, } \\
\text { Mon t e - } \\
\text { c r i s t i }, \\
\text { G u a y a - } \\
\text { quil }\end{array}$ & 31600 & 8000 & Borbón* & $\begin{array}{l}\text { Como fábrica cerró } \\
\text { en Borbón en } 1975 \\
\text { por problemas } \\
\text { laborales, reabrió } \\
\text { en } 1977 .\end{array}$ \\
\hline CODESA & $\begin{array}{l}\text { Esmeral- } \\
\text { das }\end{array}$ & 31400 & 20000 & Quinindé & $\begin{array}{l}\text { Se ha suspendido el } \\
\text { trámite. }\end{array}$ \\
\hline $\begin{array}{l}\text { E C U A - } \\
\text { D O R I A } \\
\text { M LUM- } \\
\text { BRE O }\end{array}$ & $\begin{array}{l}\text { Borbón, } \\
\text { G u a y a - } \\
\text { quil }\end{array}$ & 9532 & 8000 & Borbón & $\begin{array}{l}\text { Aumento de la con- } \\
\text { cesión negada. } \\
\text { La mayor parte de } \\
\text { la concesión está } \\
\text { colonizada. }\end{array}$ \\
\hline TADESA & $\begin{array}{l}\text { Esmeral } \\
\text { das }\end{array}$ & 20.000 & 18.000 & $\begin{array}{l}\text { Viche- } \\
\text { Quinindé }\end{array}$ & \\
\hline
\end{tabular}

Fuente: Carrasco Op cit, 65

Elaboración: El autor

Además de las industrias asentadas tanto en Borbón como en San Lorenzo, para esa fecha también se asentaron en los mismos centros poblados una cantidad considerable de aserraderos de rueda, que conjuntamente con la presencia de motosierras, completaban el círculo de la tala del bosque con fines comerciales. Todo esto tuvo un efecto económico obvio, creó un centro dinámico de comercio y de movimiento de personal que implicó la colonización con fines de agricultura, como veremos en el siguiente acápite. 


\subsection{El Período 1983- 1993}

Este es el período en que de acuerdo a Sierra, se incrementó la tala del bosque, pues prácticamente se triplicó pues pasó de 56552 ha en 1983 a 152227 ha en 1993. En este período se cumplieron varios presupuestos para la ampliación de la tala del bosque, tanto por tala comercial, así como por colonización. Entre otras, se terminó de construir la carretera Esmeraldas-Borbón, con lo cual se facilitó la transportación de la madera por vehículo directamente hasta Quito.

En este período la tala se adentro hacia las partes altas de los ríos Onzole, Cayapas, Santiago. Se configuraron tres áreas con altas tasas de deforestación superiores al 70\% o más: a lo largo del río Santiago entre Borbón y Maldonado; de Maldonado a tierra adentro siguiendo el estero Santa María; así como a lo largo del río secundario Zapallo Grande y el valle del Sade. (Sierra: op cit, 51) el otro $30 \%$ estaría concentrado en el río Onzole, y la costa, a lo largo del Santiago en área de influencia de Selva Alegre y en el bajo río Canandé. El resto del área fue deforestado antes de 1983

Cuadro No. 4

Deforestación en el período

\begin{tabular}{|c|c|c|c|c|c|c|}
\hline \multirow[t]{2}{*}{ Tipo de uso } & \multicolumn{2}{|c|}{1983} & \multicolumn{2}{|c|}{ Cambio 1983-1993 } & \multicolumn{2}{|c|}{1993} \\
\hline & Ha & $\%$ & Ha & $\%$ & Ha & $\%$ \\
\hline Deforestado & 56.00 & $10.4^{*}$ & 95675 & $-17.5 * *$ & 152227 & $27.9 * *$ \\
\hline Bosques & 489628 & 89.6 & & $-19.5 * * *$ & 393953 & 72.1 \\
\hline Total Bosques & 546180 & 100 & & & 46180 & 100 \\
\hline Otro & 11273 & & & & 11273 & \\
\hline $\begin{array}{l}\text { Total área } \\
\text { de estudio }\end{array}$ & 557453 & & & 557453 & & \\
\hline
\end{tabular}

Fuente: Sierra, R, 1996, 124

Elaboración: El autor

* Basado en el área original boscosa de 546180 ha (557 453-11 273)

** Basado en el área de bosque para 1983

*** Humedales, humedales drenados, etc. 
No obstante la información presentada por Sierra, si tomamos los datos de la Unidad Coordinadora: 1996, 6. La tasa neta de deforestación sería mucho más alta por causa de la colonización, pues:

Hectáreas según datos existentes, el ex IERAC (hoy INDA), entre marzo de 1971 a septiembre de 1992, ha titulado 239407 ha distribuidas en 1742 propiedades, a esto hay que sumarle las nuevas titulaciones que ha realizado el INDA (hasta 1996) 60000 ha a la comuna Río Santiago - Cayapas ${ }^{12}, 10400$ ha a la comuna Playa de Oro. Todo esto suma 309807 ha, superando en 98829 la superficie bajo su administración. A más de esto, existen reclamos de adjudicación por parte de la Federación de Trabajadores del Noroccidente de Esmeraldas por 93829 ha y de cinco centros Chachi por 11100.

\subsection{De 1993 hasta la presente}

Desde 1993 hasta el presente, la deforestación en el Norte de Esmeraldas, se ha vuelto realmente dramática. Esta se ha visto estimulada por la apertura de vías, que ha permitido una explotación mucho más intensiva que la que se venía realizando, pues en este período la región se vio integrada al resto país con un sistema vial de primer orden. Se concluyó la vía Ibarra - San Lorenzo ${ }^{13}$, así como la Marginal de la Costa, que une el sur de Manabí con Esmeraldas y San Lorenzo hasta Mataje en el límite con Colombia; pasando por Borbón y Maldonado. Pero además se construyó la vía Maldonado - Selva Alegre; así mismo se terminó el ramal que conecta Ricaurte-Santa Rita y San Francisco por una parte y por otra el ramal San Lorenzo-Yalaré-Concepción-Winbicito; San Lorenzo-Ricaurte y otros ramales.

Esta red vial que responde hasta cierto punto a demandas de integración de las propias comunidades locales, han sido sin duda el motor para la tala del bosque con fines comerciales y también para el

\footnotetext{
12 En realidad, la comuna Río Santiago - Cayapas, aún no tiene el título de propiedad de sus tierras, este se encuentra esperando el fallo de última instancia en el MAG (Ministerio de Agricultura y Ganadería).

13 Con esta vía se cumplió al fin el viejo sueño de la apertura del camino a Esmeraldas que las elites de la Sierra Norte habian mantenido desde la época de la colonia.
} 
cambio del uso del suelo con fines de producción de tipo agrícola y agro industrial. En términos de la explotación maderera se pasó de un tipo artesanal realizado por las comunidades locales a uno mecanizado con la presencia de tractores forestales con el cual el daño al bosque es aún mayor (Ramírez, A: 2000, 13).

En relación a la tasa de deforestación para el período en referencia, Ramírez, estableciendo un porcentaje de la deforestación nacional de 150000 ha por año, de las cuales Esmeraldas aporta con un porcentaje de entre el 15 y $20 \%$, la deforestación para Esmeraldas sería de entre 22500 a 30000 ha por año de las cuales el 60\% corresponde al norte de la provincia, por lo tanto la tasa de deforestación sería del orden de 13500 a 18000 ha por año, es decir que en los diez años se deforestó de 135000 ha a 180000 ha prácticamente el doble que en la década precedente (Ramírez: op cit, 17). Este mismo autor, realiza cálculos en torno al tiempo de duración del bosque que él sitúa en 18 años, si se mantiene la tasa actual de deforestación mínima de 13500 ha y de reforestación máxima de $10 \%$ al año, por lo tanto en 25 años cuando ya no existan bosque primario en la zona norte, los únicos espacios boscosos serían 35000 ha de bosques plantados. Todo esto en un ambiente de total desorden en cuanto se refiere a presencia de la autoridad forestal y capacidad para aplicar la Ley y el control forestal correspondiente: De ahí que sostengo, que la zona norte es un área sin presencia real del Estado, donde cada actor actúa y hace aquello que cree más conveniente para sus propios intereses, pero que a largo plazo termina por perjudicar a la región ${ }^{14}$.

Sin embargo, de acuerdo a (Janka \& Lobato: 1998, 8), la situación de Esmeraldas sería típica de otras regiones de América Latina. Con

\footnotetext{
14 Los intereses más visibles son los de las empresas, los intermediarios locales y los dueños del bosque. Casi siempre los intermediarios de la madera se han opuesto a toda forma de control por parte de la autoridad forestal. Ellos se opusieron cuando se estableció la Nueva Normativa Forestal y presionaron para que se les asigne un cupo de $10000 \mathrm{~m}^{3}$ para ser movilizados con las licencias de árboles remanentes. También se movilizaron cuando en San Lorenzo se quiso obligar a las empresas palmicultoras para que apliquen la ley ambiental y fueron también los que aparecieron dando la cara en el reciente conflicto en torno al control forestal que realizaba la SGS. En muchos de estos casos también han logrado involucrar a las comunidades locales (Cuaderno de campo del autor).
} 
autoridades que carecen de fuerza para instrumentar alternativas, campesinos confrontados y divididos, muy débilmente organizados; madereros que solo ven sus intereses más inmediatos, así como ONGs aisladas y con efectos muy puntuales.

Estos mismos autores han calificado a la situación de Esmeraldas como:

De gran desorden. Desorden motivado por la dispersión de las acciones e intereses de los organismos y actores que confluyen ahí, creándose de facto una repartición de su territorio en una serie de divisiones espaciales entre estos mismos actores. Todo esto en medio de un ambiente general de inseguridad e imprevisibilidad que limita seriamente la actividad empresarial y dificulta toda acción de gobierno.

Las consecuencias de lo anterior son la destrucción de los recursos de la región, la extracción del capital natural de la zona, la mínima reinversión en el lugar, lo que ha conducido a la pobreza extrema de su población y a su fácil manipulación política, además del riesgo de enfrentamientos políticos y sociales en el futuro. La mayoría de estos actores desean que esto cambie: Es evidente que actuando por sí mismos, actuando aisladamente, no tienen la capacidad de operar el cambio y de transformar esta situación. Contribuyen, por el contrario, a la situación descrita (Janka \& Lobato: op cit, 9).

\subsection{Los impactos de la tala del bosque}

Se pueden identificar varios efectos de la tala del bosque, siendo entre ellas las siguientes:

En primer lugar la tala del bosque con fines comerciales ha logrado desarticular las formas tradicionales de acceso de la población local a la naturaleza y sus recursos, pasando de una relación de economía de subsistencia, a una relación de dependencia con los mercados y sus productos y si bien Sierra: Op cit 54-60 sostiene que las poblaciones locales tanto Chachi, como afro ecuatorianos, así como colonos recién llegados pudieron manejar una doble estrategia, al vincularse al mercado y mantener las actividades de subsistencia, obteniendo de la relación con el mercado recursos para dedicarlos a las prácticas de subsistencias convirtiendo estas en una especie de estop de recursos, en la práctica 
parece que esa relación terminó por hacer a las poblaciones locales dependientes de los recursos del mercado y debido a su permanente tendencia a la baja de los productos del bosque en el mercado local y nacional, la población terminó por empobrecerse hasta niveles alarmantes. Como se desprende del análisis de dos indicadores sociales: índice de pobreza y educación.

Cuadro No. 5

Indicadores de pobreza

\begin{tabular}{|l|c|l|l|l|l|l|}
\hline Cantón & \multicolumn{2}{|c|}{$\%$ de pobreza } & \multicolumn{3}{c|}{$\%$ de pobreza extrema } \\
\hline & $\begin{array}{l}\text { Sector } \\
\text { urbano }\end{array}$ & $\begin{array}{l}\text { Sector } \\
\text { rural }\end{array}$ & Total & $\begin{array}{l}\text { Sector } \\
\text { urbano }\end{array}$ & $\begin{array}{l}\text { Sector } \\
\text { rural }\end{array}$ & Total \\
\hline $\begin{array}{l}\text { San } \\
\text { Lorenzo }\end{array}$ & $76.1 \%$ & $87 \%$ & $81 \%$ & $23.1 \%$ & $37.1 \%$ & $29 . \%$ \\
\hline $\begin{array}{l}\text { Eloy } \\
\text { Alfaro }\end{array}$ & $76.3 \%$ & $86 \%$ & $83.9 \%$ & $27.4 \%$ & $35.3 \%$ & $33: 6 \%$ \\
\hline $\begin{array}{l}\text { Promedio } \\
\text { provincial }\end{array}$ & $46.3 \%$ & $66.3 \%$ & $69.1 \%$ & $10.7 \%$ & $24.1 \%$ & $14.1 \%$ \\
\hline
\end{tabular}

Fuente: Censo 2001

Elaboración: el autor

Veamos a continuación los indicadores de educación:

Cuadro No. 6

Indicadores sobre educación

\begin{tabular}{|l|l|l|l|l|}
\hline Indicadores & $\begin{array}{l}\text { San } \\
\text { Lorenzo }\end{array}$ & $\begin{array}{l}\text { Eloy } \\
\text { Alfaro }\end{array}$ & $\begin{array}{l}\text { Provincia } \\
\text { de Esmeraldas }\end{array}$ & País \\
\hline $\begin{array}{l}\text { Analfabetismo en mayores } \\
\text { de 15\% años. }\end{array}$ & 21.8 & 24.5 & 14.5 & 11.7 \\
\hline $\begin{array}{l}\text { Años promedio de escolaridad } \\
\text { en la población adulta. }\end{array}$ & 4.5 & 3.9 & 5.7 & 6.7 \\
\hline $\begin{array}{l}\text { Población con acceso a } \\
\text { educación superior \%. }\end{array}$ & 6.3 & 5.4 & 10.9 & 14.1 \\
\hline
\end{tabular}

Fuente: INFOPLAN 1999

Elaboración: El autor 
Existen comunidades, como el caso de la parroquia Telembí donde el índice de analfabetismo alcanza hasta al 90\% de la población (Censo del 2001).

Otro de los impactos que ha tenido la tala del bosque, ha sido los conflictos que ha generado entre las comunidades, dentro de las mismas comunidades y entre individuos particulares y las comunidades. Esto se produce por cuanto al no existir bosque cercanos para talar y vender, las personas invaden los terrenos de los vecinos y se producen los conflictos; pero otro tipo de conflictos se presentan porque las empresas intentan arrendar el bosque de las comunidades para realizar la explotación de sus bosques por un tiempo determinado, a cambio de ciertos servicios sociales como educación, salud o la apertura de vías. Ese ha sido el caso de las comunidades Chachi del Encanto, Capulí y Gualpí1 ${ }^{15}$. Pero también es la forma de operar que tienen los contratistas de las empresas. Normalmente realizan convenios con las comunidades para extraer la madera, por la que les pagan un precio mínimo y a cambio les ofrecen el pago de maestros en las escuelas (el pago rara vez supera los 100 USA por mes) este pago dura solo hasta que el maderero está realizando la extracción; una vez que esta termina, también termina el pago al maestro, que siempre es alguien de la misma comunidad. En otros casos la negociación implica la apertura de un camino que solo es transitable en el verano $^{16}$.

Un tercer nivel de impacto tiene que ver con el hecho de que las empresas madereras, en muy pocas ocasiones realizan la explotación del bosque de manera directa, por lo tanto no se responsabilizan de daños a terceros, ni por el pago de prestaciones sociales, ni seguros contra accidentes de sus trabajadores ${ }^{17}$. La estrategia que utilizan para el efecto es mantener contratos con un conjunto de actores que son los siguientes:

15 Para el análisis de estos conflictos ver Robalino, M, 1997:361-400.

16 Estos caminos de todas maneras tendría que hacerlo el maderero para extraer la madera, pero logra por esta negociación un subsidio por parte de los dueños del bosque en su inversión, con lo cual el precio que cobran los dueños del bosque se vuelve irrisoria.

17 Carrasco Op cit, 63 narra un testimonio desgarrador de obrero de una empresa que accidentó, pidió permiso para hacerse atender, el mismo no le fue concedido. El obrero salió a su domicilio después de concluir su jornada muriendo después de una hora. 
1. Comunidades negras, con formas de trabajo familiar, responsables de la recolección y el transporte del producto, hasta el sitio de "entrega" a la empresa.

2. Compiladores contratados, que median entre el productor y la empresa, responsables de mantener la relación directa con los productores y recolectores, compilar y calificar el producto en la rivera del río y transportarlo; y

3. trabajadores asalariados, contratados por la empresa, para la recolección, calificación, embalaje y más tareas administrativas.

4. Intermediarios externos a quienes se les provee de máquina forestal para realicen la extracción y entreguen la madera en el patio (Sierra: Op cit; Ramírez, 2000).

Pero el impacto mayor tiene que ver con la destrucción de los ecosistemas de la región, que ha implicado un cambio radical del uso del suelo, con un impacto profundamente negativo para la vida de las comunidades locales, pérdida de mucha de la biodiversidad que como hemos visto en muchos casos es endémica del lugar.

\section{Hacia el manejo sustentable del bosque (un intento fallido)}

Debido al ritmo vertiginoso que tomó la deforestación en Esmeraldas, particularmente en el norte de Esmeraldas, en el año de 1996 el gobierno nacional por medio del desaparecido INEFAN establece contacto con el PPF (Proyecto de Políticas Forestales de la GTZ del Gobierno de Alemania), se intentó influir para el cambio en las políticas forestales de Esmeraldas. Esto dio como resultado la conformación de la Unidad Coordinadora para el manejo sustentable de los bosques de Esmeraldas liderada por el Gobernador de la provincia de ese entonces Eduardo Beltrán Nicola.

La Unidad Coordinadora desde su inicio intentó y logró sentar en una sola mesa a varios de los actores del quehacer forestal en la provincia: estos actores fueron algunas empresas madereras, representadas por AIMA (Asociación de Industriales Madereros), ONGs y proyectos que trabajaban en la zona, técnicos y especialistas de los proyectos, organizaciones comunitarias locales y autoridades estatales vinculadas al 
área forestal y su manejo ${ }^{18}$. Su objetivo básico era definir una estrategia que permita el manejo del bosque a largo plazo, en base a la racionalización del manejo forestal, el establecimiento de planes de manejo, y el establecimiento de mecanismos para la comercialización de la madera por parte de los propios actores del bosque, siempre y cuando estos provengan de bosque con planes de manejo legalizados por la autoridad forestal correspondiente.

El nuevo modelo de manejo forestal tenía como base la experiencia que la cooperación había realizado en México en el Estado de Quintana Roo ${ }^{19}$. Este modelo de manejo forestal tiene como base la planificación de las áreas forestales en las cuales se establecen áreas producción forestal permanente, con cuarteles de aprovechamiento anuales, áreas de reserva y diámetros de corta mínimo para las especies comerciales, así como áreas para la actividad agrícola. El modelo buscaba también la creación de un frente de organización para la comercialización de la madera y un sistema de administración forestal del bosque por parte de las comunidade ${ }^{20}$ de tal manera que estas tengan su propio equipo técnico, tal como ocurre con las Sociedades Forestales en Quintana Roo y Campeche en México. "Se trata de ir valorizando la selva para que los campesinos tengan interés en ir creando un sistema de control espacial que defienda las áreas de aprovechamiento forestal frente a otros usos" (Janka \& Lobato: op cit, 11).

El modelo empezó a implementarse en la provincia a partir del año de 1996, cuando se trabajó con 5 comunidades que tenían un área forestal de 8500 ha y se logró comercializar $100 \mathrm{~m}^{3}$ de madera rolliza, con un incremento de los precios de 22 dólares a 35, lo que tuvo un impacto positivo en las economías de las comunidades; pero creó preocupación en los intermediarios que eran los que ganaban este margen.

Para el año 1998 cuando ya se había creado la Red Forestal Comunitaria, se trabajó con 19 comunidades en un área de 65000 ha y

18 Dos actores básicos y de mucha influencia a nivel local que no fueron invitados son los intermediarios de la madera aglutinados en la Asociación de madereros y los campesinos mal identificados como colonos.

19 Se trata del Plan piloto Forestal implementado en el Sur del Estado de Quintana Roo.

20 Para un estudio completo del modelo ver: Argüelles A y Armijo N 1995; Janka: 1998, 1999; Zabin 1998; Taylor, 1998. 
se lograron comercializar en Borbón $3500 \mathrm{~m}^{3}$ de madera rolliza a un precio de 58 USA $^{21}$. Para el año siguiente se intentó trabajar con 29 comunidades u un área forestal de 80000 ha, de las cuales se tenía previsto extraer entre 6000 y $10000 \mathrm{~m}^{3}$ de madera rolliza a un precio de entre 50 y 60 USA; pero ahí empezaron los problemas y esto no se cumplió ${ }^{22}$.

Posteriormente, al siguiente año, con la finalidad de continuar con la propuesta de la comercialización y el apoyo al manejo forestal sostenible, tres instituciones que venían trabajando en el proceso: CIDESA, FEPP y PPF-GTZ conformaron el Consorcio (COFOR). Este Consorcio logró articular a 19 comunidades, las mismas que tenían bajo su control 48366 ha (Ramírez: op cit, 18). Este consorcio realizó dos ejercicios de comercialización en dos años consecutivos, pero con resultados negativos, por lo que el mencionado Consorcio se deshizo.

La terminación del proyecto SUBIR con su consecuente salida de la región, la disminución de fondos para otras ONGs que encontraban trabajando en la zona, marcaron el decaimiento de esta propuesta, que a todas luces parecía ser una alternativa para el manejo del bosque. En este momento, queda perseverando en el intento el Proyecto MFE (Proyecto de Manejo Forestal Esmeraldas) financiado por la GTZ, que se ejecuta a través del componente manejo sostenible de bosques y áreas protegidas. Las líneas de acción están relacionadas con:

- Fortalecimiento de organizaciones locales y regionales.

- Consolidación del co-manejo de áreas protegidas.

- Desarrollo e implementación de modelos replicables para el manejo sostenible de bosques.

- Apoyo al MAE para la formulación e implementación de políticas y normas

- Fortalecimiento de las capacidades locales.

21 Este fue el precio inicial, sin embargo por los problemas del fenómeno del Niño que implicó la destrucción de la carretera Esmeraldas-Borbón los precios de la madera cayeron hasta llegar a 40 USA el $\mathrm{m}^{3}$.

22 Los problemas se presentaron fundamentalmente en la comercialización y en obtención de la madera para la comercialización. El Proyecto SUBIR sentó su posición en el sentido de que solo se podría comercializar madera que provenga de planes de manejo, previamente aprobados por la autoridad forestal. Esto más los problemas de la comercialización dejaron sin sustento el trabajo que se venía realizando. 
El objetivo planteado es que las comunidades y propietarios de bosques del norte de la provincia de Esmeraldas, manejan sus recursos forestales y agroforestales en una forma autónoma y sustentable.

La estrategia del MFC es: manejo sostenible de bosques, certificación forestal, agroforestería y fortalecimiento organizacional. El programa pretende contribuir para el manejo sostenible de los recursos naturales y para el desarrollo y aumento de la calidad de vida de la población.

El proyecto se ejecuta en tres comunidades: una de población Afro Ecuatoriana (Arenales) y dos Chachi (Capulí y Gualpí). Esto indica claramente que la propuesta del manejo sustentable del bosque ha perdido impulso, tanto por parte de las instituciones, como de las comunidades. Tanto es así que la propia Unidad Coordinadora se encuentra en una fase reconstitución y de orientación de sus acciones.

$\mathrm{Si}$ se tratara de establecer las razones por las cuales esta propuesta no prosperó como se esperaba, anotaría las siguientes.

a) En primer lugar no estuvieron todos los actores. Por ejemplo, no participó la Comuna Río Santiago Cayapas que es el lugar de donde más madera se extrae y posee 61800 ha de bosque. Sus dirigentes siempre jugaron a favor de ciertas empresas o varios de ellos eran intermediarios entre las comunidades y las empresas.

b) Este modelo, se constituía en una amenaza para los intermediarios de la zona por lo que estos recurrieron a todos medios posibles con el fin de boicotearlo.

c) El modelo de comercialización implementado era demasiado lento y burocrático, que no satisfizo las expectativas de los productores locales. El modelo implicaba pago en cheques, la no entrega de anticipos, demora de por lo menos 10 días para cobrar después de una entrega de madera. Pero sobre todo ponía en riesgo las alianzas de tipo simbólico y parental que históricamente habían mantenido con los intermediarios de la zona. Estos entregan anticipos de contado y por largo tiempo, brindan apoyos extra comercial, como puede ser cuando la familia de un proveedor se enferma, le apoyan con medicinas, alimen- 
tación e incluso con licor y equipos de música o los uniformes de los equipos de fútbol en la época de fiestas ${ }^{23}$.

d) Existieron discrepancias entre las instituciones líderes. En muchos casos la posición del Proyecto SUBIR no coincidía con las del PPF y las del FEPP, por decir un ejemplo.

e) Faltó apoyo y liderazgo de parte del Estado para sacar adelante la propuesta y la pregunta de fondo sería, ¿estaban convencidas de este modelo las empresas, los otros actores del quehacer forestal de la región y las mismas comunidades?

$\mathrm{Al}$ respecto Argüelles y Armijo sostienen que:

El Plan de manejo busca reducir al mínimo los riesgos ecológicos de los aprovechamientos forestales, esto se debe a que no existe una metodología experimentada de manejo de bosques tropicales en México. También trata de minimizar los riesgos económicos del desarrollo de la empresa forestal campesina. Se toma como premisa que no ser redituable el negocio, se desalentarían los propósitos conservacionistas de los campesinos. La aceptación por parte de los campesinos es una precondición necesaria para que el plan de manejo tenga posibilidades de implementarse.

Es posible que algunas de las premisas consignadas en la cita anterior, los productores locales hayan sentido que no se estaban cumpliendo y por lo tanto no se arriesgaron a jugarse enteros por un modelo que no era familiar para ellos. Es una clara lógica de acción racional en la economía que calcula las perdidas y las ganancias.

Otro elemento que puede explicar por qué no se avanzó más, tiene que ver con un aspecto estratégico que ha sido señalado por Janka \& Lobato: op cit, 10, en el sentido de que:

Tanto las ONGs como las entidades gubernamentales no han dejado atrás ciertas posiciones poco realistas que se convierten fácilmente en ficciones. En condiciones como las de Esmeraldas se pretenden

\footnotetext{
23 El autor trabajó de 1995 al 2001 en la zona y pude registrar varias de las situaciones anotadas. El modelo de comercialización planteado es un modelo claramente de tipo monetario para no decir capitalista, que no toma en cuenta los aspectos culturales y simbólicos de los actos económicos que realizan las personas.
} 
desde el principio, iniciar con propuestas que, a corto plazo, vayan a lograr el desarrollo sustentable o un desarrollo integral. Los hechos han demostrado que así, con este enfoque, no se ha podido avanzar. En Esmeraldas se han instrumentado muchos proyectos nacionales e internacionales que con una visión integral han pretendido enfrentarse desde el principio a todos los problemas con muy poco éxito.

Efectivamente en la región se han desarrollado una serie inmensa de proyectos de todo tipo, pero siempre el énfasis está puesto en la conservación, el medio ambiente y la superación de la pobreza: Janka establece en 25 millones de dólares los fondos obtenidos; sin embargo la realidad de depredación del bosque y de pobreza se mantiene tercamente inalterable.

\subsection{Hacia una nueva estrategia ambiental}

Frente a la situación de tala insostenible del bosque y la degradación del ambiente, nuevamente varias Organizaciones e instituciones se plantean una estrategia para el manejo ya no solo del bosque, sino de toda la biodiversidad existente en la Región del Chocó. Esta nueva estrategia está liderada o apoyada por la WWW sede Colombia y busca articular y concertar con todos los actores de la región políticas que permitan manejar los recursos y mejorar las condiciones de vida de la población.

El mes de julio del 2003 se reunieron en Esmeraldas, en una mesa de diálogo para definir una estrategia para el manejo de la biodiversidad en la Región, la misma que definió las áreas para la elaboración de la estrategia y son las siguientes.

- Fortalecimiento de los actores.

- Manejo sostenible de los recursos naturales, en cuyo contenido debe incluirse su valoración económica.

- Ordenamiento territorial.

- Aplicación de políticas y normativas.

- Derechos sociales: educación, salud y seguridad alimentaria.

- Financiamiento ${ }^{24}$.

24 Los datos provienen de la memoria de la mesa de diálogo realizada en Esmeraldas el 9 de junio de 2003 
Los criterios para el diseño de esta estrategia es mucho más amplia que la anterior, por cuanto plantea en primer lugar incorporar a los actores del poder político local.

"El proceso debe incorporar a todos los gobiernos seccional y local de la provincia, esto es al Consejo Provincial, Municipios y Juntas Parroquiales.

La estrategia debe ser formulada con la participación de todos los actores de la provincia, entre los cuales se debe incluir a la comunidad". Este paso puede evitar los errores del pasado.

\subsection{Las propuestas de las Organización afroecuatorianas e indíge- nas frente a la destrucción de la naturaleza}

A partir de la década de los 90 empezó en todo el Pacífico colombiano un movimiento organizativo de las comunidades negras, con miras a consolidarse como un movimiento social, el mismo que entre sus demandas tiene como ejes las demandas por el territorio, la identidad étnico-cultural y la demanda de un espacio territorial para ejercer su poder político territorial (Escobar, A: 2001; 1999) dentro de los límites que establece la constitución y las leyes de la República.

Un proceso parecido se inició en nuestro país, con las comunidades afro ecuatorianas del norte de Esmeraldas que ellos denominan "Proceso de Comunidades Negras" o "El Proceso". Entre las demandas del Proceso de Comunidades Negras, se encuentra la demanda del territorio, el mismo que estaría consignado en el concepto de Tierras de Posesión Ancestral que reconoce la Constitución Política del Estado en su artículo 84.

"El territorio (sostienen), es donde están asentados todos los pueblos negros, y (sobre el cual le asiste) el derecho ancestral para ser y hacer, con todas sus riquezas cultural, biológica, social y política" ${ }^{\text {"25 }}$.

La clave del concepto de territorio radica entonces la capacidad que el pueblo tenga para decidir de manera autónoma sobre sus recursos y riquezas. Las tierras sobre las cuales se ejercerá el poder territorial son las del "Asentamiento ancestral", el mismo que estaría orientado por una doctrina, y que es considerado "un conjunto de ideas y principios con los

25 Ibidem. 
que un grupo de hombres viven en armonía con el universo y lo ayudan a entender de mejor manera su propio ser, su existencia y la de todos los seres del universo.

Lo tradicional también es filosofía, porque es ante todo una forma de vivir y de pensar que el hombre recibe de su grupo social como una enseñanza que se recibe de generación en generación, etc. Siendo así, el Asentamiento Tradicional o Ancestral es el derecho elemental que un grupo étnico tiene a vivir de acuerdo a su doctrina y con su propia filosofía en una tierra que por historia y por derecho de posesión le pertenece desde su nacimiento como pueblo o como grupo" (García, Juan, 1994).

Este conjunto de ideas, que es para los afro descendientes a la vez filosofía, se aplicará para la administración del territorio por medio de las circunscripciones territoriales o palenques, que ha sido definido de la siguiente manera:

Circunscripción territorial afroecuatoriana o palenque, es el espacio físico, político, administrativo delimitado donde se ejercen colectivamente los derechos políticos, económicos, sociales, culturales y administrativos del pueblo afroecuatoriano; comprende la totalidad del hábitat natural que ocupa y posee ancestralmente el pueblo afro ecuatoriano en donde desarrollan sus particulares formas de vida, sus diferentes manifestaciones sociales, políticas, económicas y culturales ${ }^{26}$.

Los elementos de la circunscripción territorial serían:

Territorio geográfico determinado;

población afroecuatoriana;

identidad de pueblo;

autoridades propias;

autonomía política y administrativa;

instituciones administrativas propias; $y$, patrimonio $^{27}$

De tal manera que frente a los procesos de destrucción de la naturaleza, del cual la deforestación es solo un elemento, las organizaciones locales plantean un proyecto de autonomía política que les permita con apego a su cultura manejar la naturaleza y sus recursos dentro de un modelo de desarrollo con identidad cultural que no ponga en riesgo la naturaleza. Este modelo estaría inspirado en aquello que sostiene que el capital no busca la sostenibilidad de la naturaleza, sino la sostenibili-

26 Consejo Regional de Palenques, 199... 3.

27 Ibídem, 3. 
dad del capital. Porque como sostiene Martínez Alier (Citado por Escobar: 1999, 82).

La idea de que el crecimiento económico es "bueno" para el ambiente no puede ser aceptada... Un crecimiento económico generalizado puede agravar, en vez de disminuir la degradación ambiental, aunque la misma riqueza permita destinar más recursos a proteger el ambiente causados por ella misma

Esta idea parte del análisis de que la destrucción de los recursos naturales está directamente asociada al modelo de desarrollo que una sociedad se plantea. En el caso que nos ocupa la deforestación del norte de Esmeraldas, tiene como premisa una relación entre la sociedad nacional y la naturaleza, en que esta (la naturaleza) es vista como un conjunto desagregado de recursos (agua, aire, bosque) etc., los mismos que pueden ser utilizados como formas de capital hasta su agotamiento. Sin tomar en cuenta que dentro de esa naturaleza conviven una serie de elementos de los cuales el hombre es uno más y que para las culturas locales, como indígenas y afro ecuatorianos el agotamiento de la naturaleza, es parte el agotamiento de la vida por cuanto, su vida, su cultura está ligada a ella.

En este sentido, la propuesta de las organizaciones locales, lideradas por el Consejo Regional de Palenques, lo que buscan es articular propuestas de desarrollo, que tomen en cuenta la cultura y la relación con la naturaleza, lo que implica pensar en una relación de mayor equidad, participación y respeto a las culturas locales y sus visiones del desarrollo. Por lo tanto el tema de manejo de los recursos naturales, el control y acceso a los mismos deja de ser una cuestión técnica (que lo es en el nivel operativo) para convertirse en una cuestión de poder y por lo tanto esencialmente política.

Al respecto, mi opinión es que este proyecto no es fácil llevarlo adelante, debido principalmente a que la misma población ha sido dividida por los actores económicos y políticos que operan en la región, que hace que no miren sus intereses de manera coherente y a largo plazo; de esta situación coyunturalista sacan ventaja los interesados en explotar el bosque y la naturaleza a toda costa.

Pablo de la Torre (presidente de FEDARPOM SL), tiene fe que es posible articular un proceso político que parta de la base de las culturas locales y que se pueda realizar una aprovechamiento racional del 
bosque (con múltiples racionalidades más bien sería, porque hasta ahora ha estado presente una sola, la de la extracción capitalista) para que lo que queda del bosque primario pueda ser salvado. Él está de acuerdo con Arturo Escobar, cuando sostiene que:

...Las comunidades locales necesitan hoy en día experimentar con formas productivas y organizativas alternativas y, al mismo tiempo, practicar una resistencia semiótica y cultural de la reestructuración de la naturaleza efectuada por la ciencia y el capital en su fase ecológica. El balance de estas dos prácticas político-culturales es precario, pero los movimientos sociales parecen abocados a ello .

De mi parte pienso que para revertir esta tendencia, el Estado debe establecer políticas que tiendan a ello. Pero es más importante que la sociedad nacional no permanezca indiferente; pues el problema de la destrucción de la naturaleza, al fin y al cabo es un problema de la humanidad.

28 Conversación personal con Pablo de la Torre, con miras a la preparación de este artículo. Uno de los pasos que la organización ha empezado a dar para realizar esta resistencia cultural y discursiva, es la puesta en marcha de la escuela de formación de líderes Martín Luther King. Porque como él dice si no formamos a las nuevas generaciones en una perspectiva distinta, no tenemos posibilidades. 
